\title{
Sabbatical Journey of Discovery: Recruitment, Retention and Quality of Work Life
}

\section{Mary Ferguson-Paré}

Vice President, Professional Affairs and Chief Nurse Executive University Health Network, Toronto, ON

This is the fourth in a series of reports to share key learnings from my 2005 sabbatical, when I took a three-month journey through Scandinavia, Western Europe, Ireland and the United Kingdom to observe innovation in nursing services delivery. The focus of this report is recruitment, retention and quality of work life. All the countries I visited were addressing these issues to deal with the global health human resources shortage we all face.

\section{Quality of Work Life}

A variety of approaches are being utilized in various countries that support the advancement of quality of work life. As we know, leadership has a significant impact on nurses' quality of work life. The behaviour of the person to whom a nurse reports is influential in creating an environment that either supports the retention of nurses or drives them away.
The Royal College of Nurses (RCN) in the United Kingdom has invested in an outstanding leadership development program. When I visited Belgium, the RCN leadership development program was being implemented widely there. Researchers and nurse leaders in Belgium were also committed to the concept that promoting the professionalism of nursing is critical to helping nurses feel valued and able to produce communities of caring in hospitals. Leadership structures are seen to be key to supporting this. Nursing leadership at every level of the organization is supported, promoted and developed. Academics and nursing leaders in Belgium believe that nurses practise in the way that the environment expects, largely because of their negative self-image arising from the disparity between nursing values and the dominant values of the organization. We discussed our shared concerns regard- 
ing the moral and ethical distress that nurses often feel within the practice environment. The need for strong, supportive nursing and organizational leadership in these situations is seen as a significant contributor to quality of work life for nurses. In France, the directors of nursing had a very close relationship and leadership process with nurse managers. Directors of nursing met regularly with nurse managers and mentored them in positive, supportive leadership approaches with nursing staff.

Continuous education was seen as a significant contributor to quality of work life for nurses. Every hospital that I visited had extensive programs of inservice education and continuing education of all sorts. Opportunities for nurses to upgrade their skills and participate in specialty training and formal programs to advance them to undergraduate and graduate degrees were in evidence. In Ireland, nurses are salaried while pursing specialty education to support their continuous learning and development. Ireland is also implementing the SKILL Project to provide for-credit education and training for support service workers across the country. The European Union has

agreed on baccalaureate preparation as the entry to nursing practice and master's preparation for all advanced practice and specialist nurses.

Nursing information systems are also seen as a very important support to nurses in their practice. In Ireland, I learned about a nursing information system that integrates care planning, workload measurement and scheduling with the hospital information system.

I saw a variety of supportive equipment and physical environments in various settings to help nurses with their work. For example, in Germany 
and France, I observed the automated bed supply system and elevator. A centralized system for cleaning soiled patient equipment was in place: support staff removed used equipment such as beds, bedside tables and nursing care equipment to a central cleaning area. The made bed with sterilized bedside equipment was shrinkwrapped and returned through an automated bed supply elevator. Staff could access the equipment by pressing a button. A door would open and the bed and supplies would literally pop out of the wall, ready to go! In Belgium I observed a one-person mechanical bed mover. I had the opportunity to test it and can tell you that nurses and other personnel were able to move beds with one hand utilizing this hydraulic system. Most of the time support service personnel were available to remove and replace beds or move them among rooms on the nursing unit. Unit aides and cleaners were in evidence in Belgium and in many other countries to decant non-nursing duties.

In Sweden, workload issues were considered significant and an important influence on quality of work life. Medical unit nurses had an assignment of three to four patients per eight-hour shift. They also had a private nursing office, in addition to the nurse's station, on each wing of the floor. Nurses used this space for private meetings with patients and family, to look up online resources, and for documentation, conferencing and nursing rounds. Staff bicycles and scooters for internal hospital transportation were also in evidence in Sweden, and assisted all health professionals to move from area to area quickly.

Other recruitment and retention initiatives include retention incentives to reduce job strain for late-career nurses. In Belgium, nurses 45-50 years of age received one paid day off per month. Nurses 50-55 years of age received two paid days off per month. Nurses 55 years of age and over received three paid days off per month. A further retention strategy involved the free choice of schedule for nurses who were willing to work in full-time float positions across the hospital.

As you can see, our colleagues abroad are advancing quality of work life as a major retention strategy and focusing on retention as the answer to long-term recruitment. We can learn from these approaches to advance recruitment and retention in Canada. The supply and demand for health human resources is an international concern. Never before has there been such an imperative for us to develop the kind of leadership and quality of work life that will support nurses within the healthcare system to remain in nursing and to speak from the joy in their practice to potential candidates for the profession. When we have nurses speaking for nursing, partnered with patients and focused on health, others will want to be part of the profession.

I look forward to sharing other key learnings in future reports.

For more information, Dr. FergusonParé can be reached at: Mary.Ferguson-Paré@uhn.on.ca 